\title{
Domestic Violence against Women Detected and Managed in Dental Practice: a Systematic Review
}

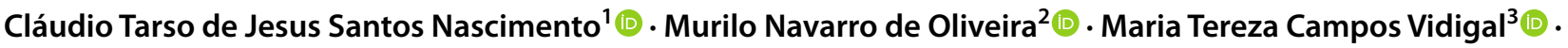 \\ Gabriel Santiago Giuglio Inocêncio ${ }^{4}(1) \cdot$ Walbert de Andrade Vieira ${ }^{5}\left([) \cdot\right.$ Ademir Franco $^{6,7,8}$ (D) \\ Meire Coelho Ferreira ${ }^{9}$ (i) $\cdot$ Luiz Renato Paranhos ${ }^{10}$ (1)
}

Accepted: 14 December 2021 / Published online: 6 January 2022

(c) The Author(s), under exclusive licence to Springer Science+Business Media, LLC, part of Springer Nature 2022

\begin{abstract}
This study aimed to investigate the knowledge of dental care professionals to identify and manage clinical situations that indicate violence against women. PRISMA guidelines were followed and a systematic review protocol was registered in PROSPERO. The systematic search was designed based on the PICo strategy. Six databases were used as primary research sources (PubMed, Scopus, LILACS, SciELO, Web of Science, and Embase). Three databases (OpenGrey, OpenThesis, and OATD) were used to detect the "grey literature". Observational studies (cross-sectional, cohort, or case-control) were included, and there were no restrictions of year or language of publication. Two authors selected and extracted the data from the eligible studies. The risk of bias was assessed with the JBI Critical Appraisal Checklist. The search resulted in 10,115 studies. Eleven met the eligibility criteria and were included in the qualitative synthesis. The studies were published from 1994 to 2018. All studies presented low risk of bias. Among the dental care professionals, only $1-7.1 \%$ of the dentists included injury search and examination of their patients for signs of violence. Less than $47 \%$ of the professionals had knowledge to identify violence injuries. When it comes to knowledge to identify signs of domestic violence, positive answers were below $24 \%$. Considering all the variables assessed in this study, dental care professionals presented deficiencies regarding the knowledge and management of situations of domestic violence against women. Educational strategies are necessary to prepare dental care professional to identify and report suspicious cases.
\end{abstract}

Keywords COVID-19 $\cdot$ Domestic violence $\cdot$ Intimate partner violence $\cdot$ Forensic dentistry

Luiz Renato Paranhos

paranhos.lrp@gmail.com

1 Postgraduate Program in Dentistry, Uniceuma University, São Luís, Maranhão, Brazil

2 Postgraduate Program in Dentistry, School of Dentistry, Federal University of Uberlândia, Uberlândia, Minas Gerais, Brazil

3 School of Dentistry, Federal University of Uberlândia, Uberlândia, Minas Gerais, Brazil

4 Program in Dentistry, School of Dentistry, Federal University of Uberlândia, Uberlândia, Minas Gerais, Brazil

5 Department of Restorative Dentistry, Endodontics Division, Piracicaba Dental School, State University of Campinas (UNICAMP), Piracicaba, São Paulo, Brazil
6 Centre of Forensic and Legal Medicine, University of Dundee, Scotland, UK

7 Division of Forensic Dentistry, Faculty São Leopoldo Mandic, Campinas, Brazil

8 Department of Therapeutic Stomatology, Institute of Dentistry, Sechenov University, Moscow, Russia

9 Postgraduate Program in Dentistry, Uniceuma University, São Luís, Maranhão, Brazil

10 Division of Preventive and Community Dentistry, School of Dentistry, Federal University of Uberlândia, Campus Umuarama, Av. Pará, 1720, Bloco 2G, sala 1, Uberlândia, MG ZIP code: $38405-320$, Brazil 


\section{Introduction}

In the World Report on Violence and Health (WRVH), the World Health Organization (WHO) defined violence as "the intentional use of physical force or power, threatened or actual, against oneself, another person, or against a group or community, that either results in or has a high likelihood of resulting in injury, death, psychological harm, maldevelopment, or deprivation" (WHO, 1996). From the environmental perspective, interpersonal violence may involve family or community. Family violence may target children, intimate partners, and the elderly. Among intimate partners, women are more susceptible and more frequently victimized (Krug et al., 2002).

Violence against women is defined by the United Nations as "any act of gender-based violence that results in, or is likely to result in, physical, sexual, or mental harm or suffering to women, including threats of such acts, coercion or arbitrary deprivation of liberty, whether occurring in public or in private life" (OHCHR, 1993). Epidemiological investigations reveal that up to $35 \%$ of women worldwide will experience gender-based violence (Flury et al., 2010). Similarly, WHO specifies that nearly $30 \%$ of women will face physical or sexual violence in their lives (WHO, 2018).

Regarding the current global situation, COVID-19 pandemic negatively affected the exposure of women to domestic violence. Consequently, an increased number of reports was detected (Moreira \& Costa, 2020). Investigations have indicated a major vulnerability of women to interpersonal violence in periods of lockdown and social distancing (Sánchez et al., 2020). Other authors, however, detected a decreased number of reports from victim assistance programs (Barbara et al., 2020). At first, this phenomenon could have a positive interpretation, but it also means that women are more restricted in the process of reporting violence experienced in the domestic environment. In practice, the pandemic restrictions highlighted the need for new protection strategies for women, such as applications (apps) to enable on-line reports. A recent example of tool dedicated to protecting women is the FollowIt ${ }^{\mathrm{TM}}$ app (Scottish Women's Rights Centre, Glasgow, UK) - an initiative of Rape Crisis Scotland and Media co-op. The software is not necessarily designed for domestic violence but works on-line on the protection of women that experienced stalking. While on-line reporting is under construction, violence continues - highlighting the importance of constant surveillance.

In this context, some authors claim that health care professionals have a determinant role in the identification and management of cases of violence against women (Barbara et al., 2020). An open question in this scenario is whether dental care professionals are aware and prepared to identify and manage cases of domestic violence against female patients. Therefore, a systematic literature review was designed to assess the knowledge and attitudes of dental care professionals regarding cases of violence against women.

\section{Methods}

\section{Protocol Registration}

The research protocol was prepared according to the Preferred Reporting Items for Systematic Review and MetaAnalysis Protocols (PRISMA-P) (Shamseer et al., 2015) and registered at the International Prospective Register of Systematic Reviews (PROSPERO) database, under number CRD42020198305 (http://www.crd.york.ac.uk/PROSP ERO). This systematic review was reported according to the Preferred Reporting Items for Systematic Reviews and Meta-Analyses (PRISMA) (Page et al., 2021) and conducted according to the Joanna Briggs Institute (JBI) manual (Aromataris \& Munn, 2020).

\section{Research Question and Eligibility Criteria}

This systematic review aimed to answer the following guiding question, based on the PICo acronym (Population, Interest, and Context): What is the educational background, management, perception, knowledge level, and attitude of dental care professionals regarding domestic violence against women?

\section{Inclusion criteria.}

Population: Dental care professionals of both sexes, regardless of the level of education and degree of professional training;

Interest: Educational background, management, perception, knowledge level, and attitude;

Context: Domestic violence against women;

Study design: Observational studies (cross-sectional, cohort, or case-control).

There were no restrictions on the language or year of publication.

\section{Exclusion criteria.}

Studies using secondary databases;

Surveys without specific questions on violence against women;

Studies that assessed health care professionals other than dental care related; 
Studies that did not separate the results of dental care professionals from other health care professionals;

Solely qualitative studies.

\section{Sources of Information, Search, and Selection of Studies}

The electronic search was performed in MedLine/PubMed, Scopus, LILACS, SciELO, Embase, and Web of Science databases. The OpenGrey, OpenThesis, and OATD databases were used to partially capture the "grey literature". Medical Subject Headings (MeSH), Health Sciences Descriptors (DeCS), and Embase Subject Headings (Emtree) were used to select the search descriptors. Additionally, synonyms and free words were used to improve the search. The Boolean operators "AND" and "OR" were used to connect terms. Table 1 shows the search strategies used in each database (strategies were adapted to each database, following their syntax and system). The bibliographical search ended in October 2020. The search results were exported to EndNote Web ${ }^{\mathrm{TM}}$ software (Thomson Reuters, Toronto, Canada) in order to exclude duplicates and enable better organization. The grey literature was exported to Microsoft Word (Microsoft ${ }^{\mathrm{TM}}$, Ltd., Washington, USA) for manual removal of duplicates.

Before study selection, a calibration exercise was performed, in which the examiners discussed the eligibility criteria and applied them to a sample of $20 \%$ of the studies to

Table 1 Strategies for database search

\begin{tabular}{|c|c|}
\hline Database & Search Strategy (October, 2020) \\
\hline $\begin{array}{l}\text { PubMed } \\
\text { http://www.ncbi.nlm.nih.gov/pubmed }\end{array}$ & 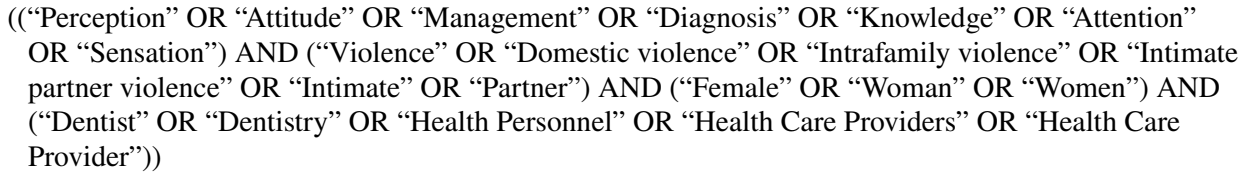 \\
\hline $\begin{array}{l}\text { Scopus } \\
\text { http://www.scopus.com }\end{array}$ & 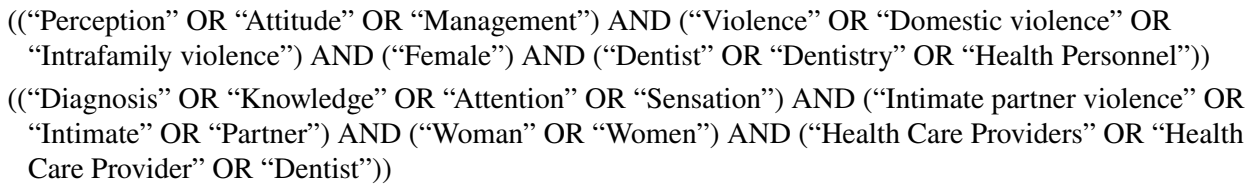 \\
\hline $\begin{array}{l}\text { LILACS } \\
\text { http://lilacs.bvsalud.org/ }\end{array}$ & 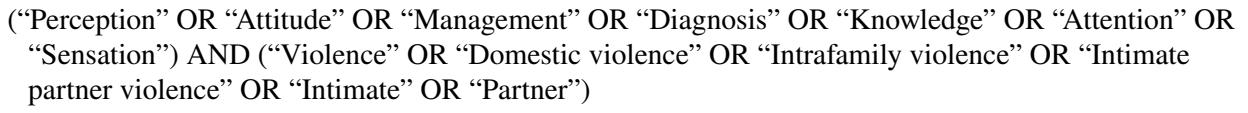 \\
\hline $\begin{array}{l}\text { SciELO } \\
\text { http://www.scielo.org/ }\end{array}$ & $\begin{array}{l}\text { ("Perception" OR “Attitude" OR “Management" OR “Diagnosis" OR “Knowledge” OR "Attention" OR } \\
\text { "Sensation") AND ("Violence" OR “Domestic violence" OR "Intrafamily violence" OR "Intimate } \\
\text { partner violence" OR "Intimate" OR "Partner") }\end{array}$ \\
\hline $\begin{array}{l}\text { Embase } \\
\text { http://www.embase.com }\end{array}$ & $\begin{array}{l}\text { ('perception' OR ‘attitude' OR ‘management' OR ‘diagnosis' OR ‘knowledge' OR 'attention' OR } \\
\text { 'sensation') AND ('violence' OR ‘domestic violence' OR ‘intrafamily violence' OR ‘intimate partner } \\
\text { violence' OR ‘intimate' OR ‘partner') AND ('female' OR ‘woman' OR ‘women') AND ('dentist' OR } \\
\text { 'dentistry' OR 'health personnel' OR 'health care providers' OR 'health care provider') }\end{array}$ \\
\hline $\begin{array}{l}\text { Web of Science } \\
\text { http://apps.webofknowledge.com/ }\end{array}$ & 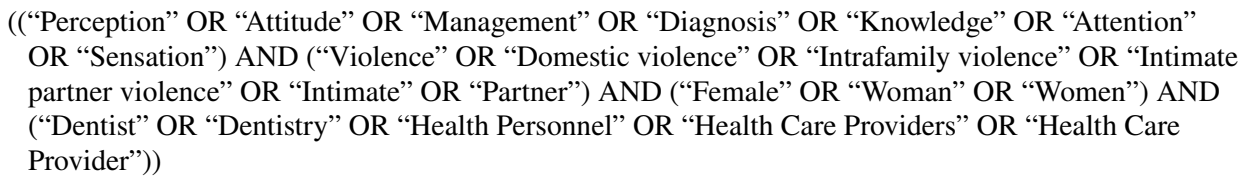 \\
\hline $\begin{array}{l}\text { OpenGrey } \\
\text { http://www.opengrey.eu/ }\end{array}$ & 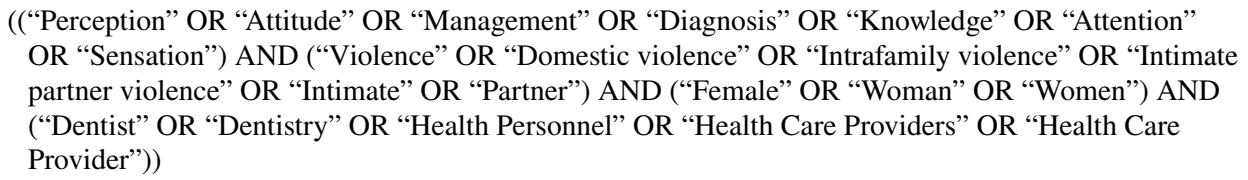 \\
\hline $\begin{array}{l}\text { OpenThesis } \\
\text { http://www.openthesis.org/ }\end{array}$ & 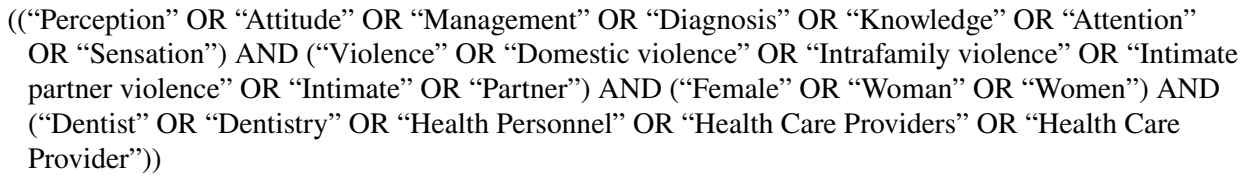 \\
\hline $\begin{array}{l}\text { Open Access Theses } \\
\text { and Dissertations (OATD) } \\
\text { https://oatd.org/ }\end{array}$ & 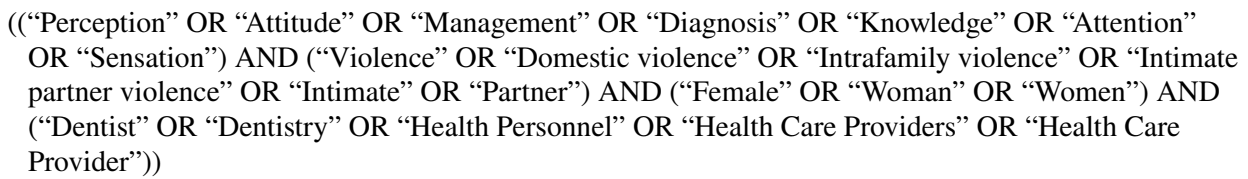 \\
\hline
\end{tabular}


determine inter-examiner agreement. Examiners were considered eligible for the subsequent phase only after reaching an agreement of Kappa $\geq 0.81$.

The results were exported to Rayyan software (Qatar Computing Research Institute - QCRI, Doha, Qatar). Title and abstract reading were performed within the software. Studies that did not fit to the research topic were excluded (first exclusion phase). In the second phase, the eligible studies underwent full-text reading to verify whether they met the eligibility criteria. The studies excluded in this phase were stored separately with the reasons for their exclusion. When the full texts were not available, a bibliographic request was performed to the institutional library and e-mails were sent to the corresponding authors. All phases were performed independently by two reviewers, and in case of doubt or disagreement, a third reviewer was consulted to make a final decision.

\section{Data Collection}

Before data extraction, to ensure consistency between the reviewers, a calibration exercise was performed between them, in which information was extracted jointly from an eligible study. Any disagreement between the examiners was settled with discussion and with the aid of a third examiner.

The following information was extracted from the studies: study identification (author, year and country of publication), sample characteristics (sample size, sex distribution, and average work experience), data collection and processing aspects (e.g. collection method: survey or interview), and main outcomes (quantity of professionals who reported educational background on the topic, quantity of professionals who included the search of signs of domestic violence during their clinical routine, quantity of professionals who reported knowledge to identify signs of violence against women, quantity of professionals who reported knowledge to manage suspicious cases of domestic violence, and the main attitudes of the dental care professionals in these cases. In case of doubt or lack of information in the eligible studies, the corresponding authors were contacted via e-mail. Up to three tentative e-mails were sent.

\section{Risk of Bias Assessment}

To analyze the risk of bias and individual methodological quality of the eligible studies, the JBI Critical Appraisal Checklist (Moola et al., 2020) was used. Two reviewers assessed independently each domain regarding the potential risk of bias - as recommended by the PRISMA statement (Page et al., 2021). Each study was categorized according to the percentage of positive answers to the questions provided within the assessment tool. The risk of bias was considered High when the study obtained $49 \%$ of "yes" answers,
Moderate when the study obtained 50\% to 69\% of "yes" answers, and Low when the study reached more than $70 \%$ of "yes" answers.

\section{Summary of Measurements and Synthesis of Results}

The results were presented narratively/descriptively and analyzing the methodological heterogeneity of the eligible studies. Absolute (n) and relative (\%) values were collected from each study, especially for participant's educational background, and their management, perception, knowledge, and attitudes in case of violence against women.

\section{Results}

\section{Study Selection}

During the first phase of study selection, 10,115 results were found. After removing duplicates, 6800 results remained for title and abstract reading-. In total, 6719 exclusions were performed. From the 81 studies that remained for full-text reading three were not retrieved, and 67 were excluded (reasons for exclusion were registered in Online Resource 1). Finally, 11 studies (Carvalho et al., 2013; Chiodo et al., 1994; Danley et al., 2004; Drigeard et al., 2012; Goff et al., 2001; Harris et al., 2016; Hsieh et al., 2006; Lea et al., 2016; Love et al., 2001; McDowell et al., 1994; Parish et al., 2018) were included in the qualitative analysis. Figure 1 represents the flowchart of the study selection procces.

\section{Study Characteristics}

The studies were published between 1994 and 2018 and were performed in four different countries: eight studies in the United States (Chiodo et al., 1994; Danley et al., 2004; Goff et al., 2001; Harris et al., 2016; Hsieh et al., 2006; Love et al., 2001; McDowell et al., 1994; Parish et al., 2018), one in Brazil (Carvalho et al., 2013), one in the United Kingdom (Lea et al., 2016), and one in France (Drigeard et al., 2012). Nine studies (Danley et al., 2004; Drigeard et al., 2012; Goff et al., 2001; Harris et al., 2016; Hsieh et al., 2006; Lea et al., 2016; Love et al., 2001; McDowell et al., 1994; Parish et al., 2018) collected data exclusively from surveys, while one study applied surveys and in-person interviews (Carvalho et al., 2013). One study collected data with surveys and via phone interview (Chiodo et al., 1994). Four studies did not report ethical aspects/criteria (Danley et al., 2004; Lea et al., 2016; Love et al., 2001; McDowell et al., 1994). None of the studies followed the STROBE (von Elm et al., 2008) guidelines for observational studies. Six studies (Carvalho et al., 2013; Drigeard et al., 2012; Hsieh et al., 2006; Love et al., 2001; McDowell et al., 1994; Parish et al., 2018) applied 
Fig. 1 Flowchart of the selection process, according to PRISMA

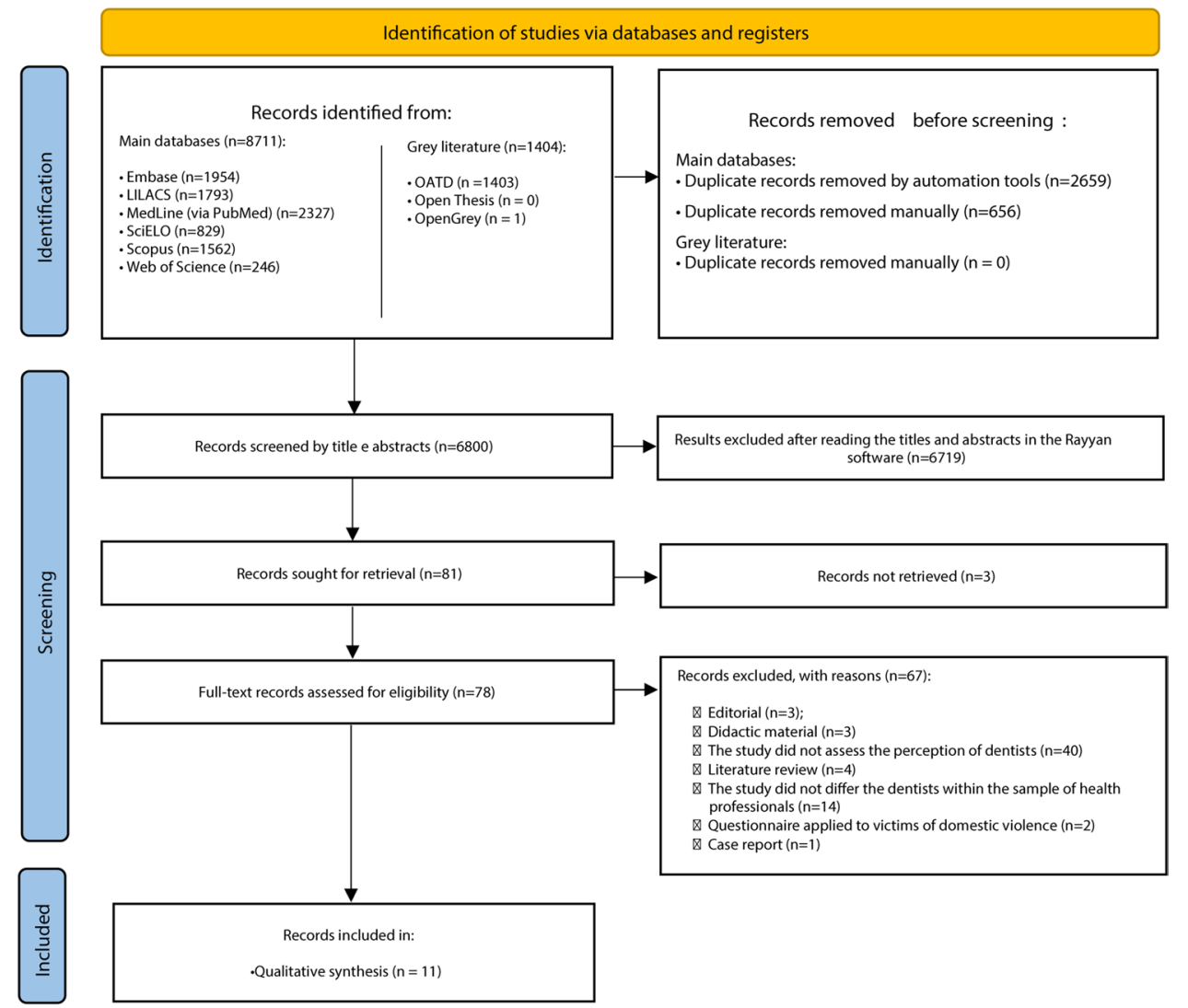

surveys exclusively to dentists, two studies applied surveys to dentists and dental hygienists (Chiodo et al., 1994; Harris et al., 2016), one study assessed dentists and dental students (Danley et al., 2004), one study assessed only dental students (Lea et al., 2016), and one study assessed dentists, physicians, and nurses (Chiodo et al., 1994). Seven studies (Danley et al., 2004; Goff et al., 2001; Harris et al., 2016; Hsieh et al., 2006; Lea et al., 2016; Love et al., 2001; Parish et al., 2018) assessed violence exclusively against female partners, while four studies (Carvalho et al., 2013; Chiodo et al., 1994; Drigeard et al., 2012; McDowell et al., 1994;) assessed domestic violence against female partners, children, or the elderly.

Among the studies that reported the number of participants included, the sum of samples resulted in 3780 participants $(21.97 \%$ females, $77.65 \%$ males, and $0.47 \%$ of individuals that did not report sex). Three studies investigated the specialized field of the involved dental care professionals (Chiodo et al., 1994; Harris et al., 2016; McDowell et al., 1994). In these studies, the combined sample was 775 participants, from which $77.41 \%$ weregeneral practitioners, $7.09 \%$ were orthodontists, $3.74 \%$ were pediatric dentists, $2.7 \%$ were periodontologists, $2.45 \%$ were maxillofacial surgeons, $2.06 \%$ were public health specialists, $1.16 \%$ were endodontists, and $0.51 \%$ were dental prothodontists. The remaining $2.83 \%$ did not reported their specialty or reported a field that was different from the above. Table 2 shows the main characteristics of the eligible studies.

\section{Assessment of the Risk of Bias of the Studies}

All the 11 studies were classified as a low risk of bias. Question 1 (referring to the eligibility criteria used in the sampling process) presented negative answers in five studies (Chiodo et al., 1994; Drigeard et al., 2012; Goff et al., 2001; Love et al., 2001; McDowell et al., 1994). This answer is important because it predicts sample standardization to decrease the risk of bias. Questions 5 and 6 were considered not applicable for all the studies because the questions refer to the confounding factors, which are applicable only in study models that include intervention or exposure. All the other questions presented positive answers. Table 3 shows the outcomes of the assessment of the risk of bias.

\section{Results of Individual Studies}

Seven studies (Carvalho et al., 2013; Chiodo et al., 1994; Goff et al., 2001; Harris et al., 2016; Love et al., 2001; McDowell et al., 1994; Parish et al., 2018) revealed the percentage of professionals who reported knowledge to identify signs of domestic violence. Six studies (Carvalho et al., 2013; Danley et al., 2004; Harris et al., 2016; Lea 


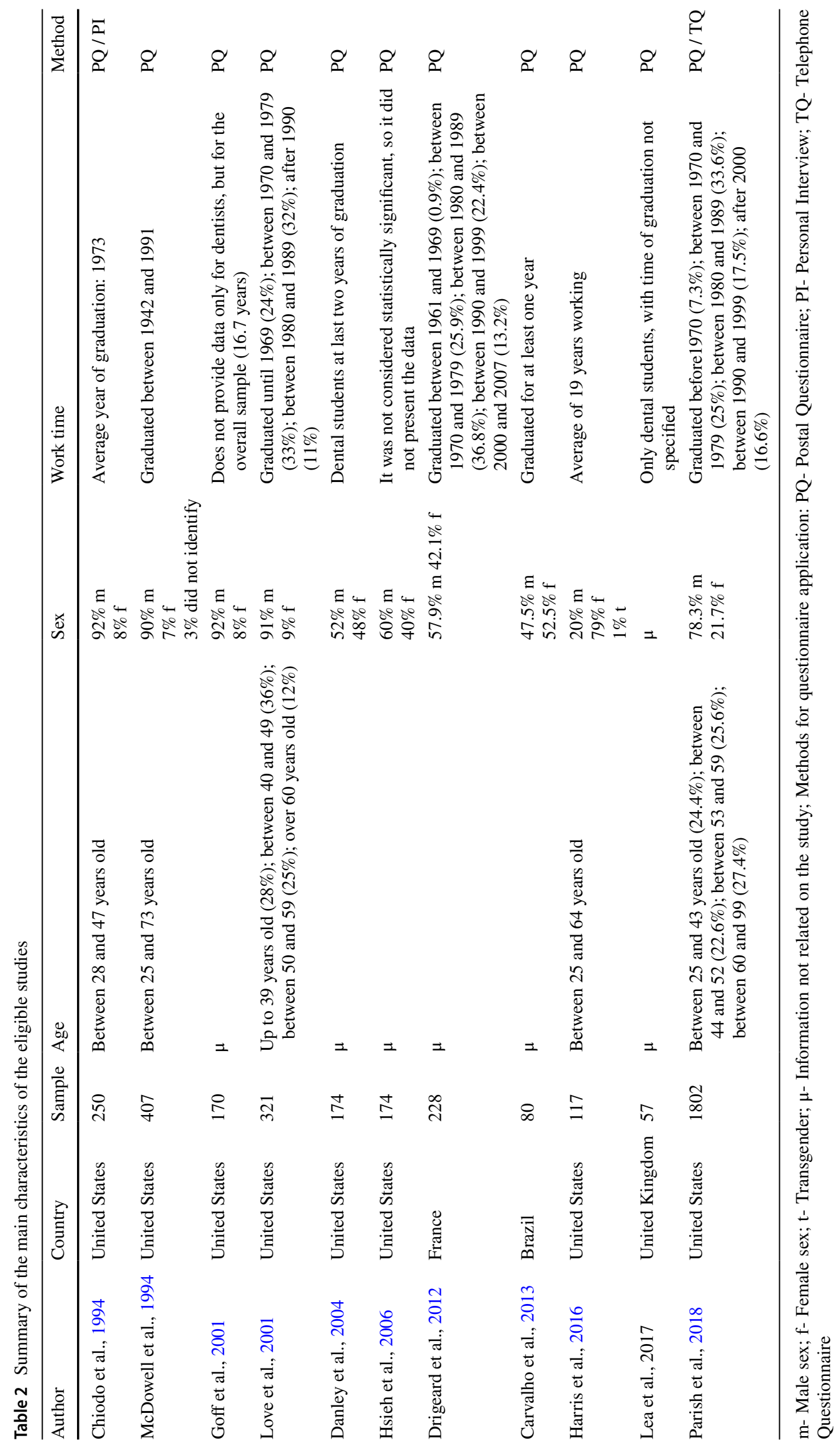


Table 3 Risk of bias assessed by the Joanna Briggs Institute Critical Appraisal Tools for use in JBI Critical Appraisal Checklist for Analytical Cross Sectional Studies

\begin{tabular}{lllllllllll}
\hline Authors & Q1 & Q2 & Q3 & Q4 & Q5 & Q6 & Q7 & Q8 & \% Yes & Risk \\
\hline Chiodo et al., 1994 & - & $\sqrt{ }$ & $\sqrt{ }$ & $\sqrt{ }$ & NA & NA & $\sqrt{ }$ & $\sqrt{ }$ & 83.3 & Low \\
McDowell et al., 1994 & - & $\sqrt{ }$ & $\sqrt{ }$ & $\sqrt{ }$ & NA & NA & $\sqrt{ }$ & $\sqrt{ }$ & 83.3 & Low \\
Goff et al., 2001 & - & $\sqrt{ }$ & $\sqrt{ }$ & $\sqrt{ }$ & NA & NA & $\sqrt{ }$ & $\sqrt{ }$ & 83.3 & Low \\
Love et al., 2001 & - & $\sqrt{ }$ & $\sqrt{ }$ & $\sqrt{ }$ & NA & NA & $\sqrt{ }$ & $\sqrt{ }$ & 83.3 & Low \\
Danley et al., 2004 & $\sqrt{ }$ & $\sqrt{ }$ & $\sqrt{ }$ & $\sqrt{ }$ & NA & NA & $\sqrt{ }$ & $\sqrt{ }$ & 100 & Low \\
Hsieh et al., 2006 & $\sqrt{ }$ & $\sqrt{ }$ & $\sqrt{ }$ & $\sqrt{ }$ & NA & NA & $\sqrt{ }$ & $\sqrt{ }$ & 100 & Low \\
Driegard et al. 2012 & - & $\sqrt{ }$ & $\sqrt{ }$ & $\sqrt{ }$ & NA & NA & $\sqrt{ }$ & $\sqrt{ }$ & 83.3 & Low \\
Carvalho et al., 2013 & $\sqrt{ }$ & $\sqrt{ }$ & $\sqrt{ }$ & $\sqrt{ }$ & NA & NA & $\sqrt{ }$ & $\sqrt{ }$ & 100 & Low \\
Harris et al., 2016 & $\sqrt{ }$ & $\sqrt{ }$ & $\sqrt{ }$ & $\sqrt{ }$ & NA & NA & $\sqrt{ }$ & $\sqrt{ }$ & 100 & Low \\
Lea et al., 2017 & $\sqrt{ }$ & $\sqrt{ }$ & $\sqrt{ }$ & $\sqrt{ }$ & NA & NA & $\sqrt{ }$ & $\sqrt{ }$ & 100 & Low \\
Parrish et al. 2018 & $\sqrt{ }$ & $\sqrt{ }$ & $\sqrt{ }$ & $\sqrt{ }$ & NA & NA & $\sqrt{ }$ & $\sqrt{ }$ & 100 & Low \\
\hline
\end{tabular}

Q1- Were the criteria for inclusion in the sample clearly defined?; Q2- Were the study subjects and the setting described in detail?; Q3- Was the exposure measured in a valid and reliable way?; Q4- Were objective and standard criteria used for measuring the condition?; Q5- Were confounding factors identified?; Q6Were strategies to deal with confounding factors stated?; Q7- Were the outcomes measured in a valid and reliable way?; Q8- Was appropriate statistical analysis used? Yes ( $\sqrt{ }$ ); No (--); Not Applicable (NA) et al., 2016; Love et al., 2001; McDowell et al., 1994) investigated whether the professionals could identify injuries that could indicate violence against women. Seven studies (Carvalho et al., 2013; Chiodo et al., 1994; Danley et al., 2004; Goff et al., 2001; Lea et al., 2016; Love et al., 2001; Parish et al., 2018) assessed whether dental care professionals had received an educational background on violence at any academic stage. Three studies (Goff et al., 2001; Love et al., 2001; Parish et al., 2018) questioned whether professionals exam their patients during routine appointments in order to look for signs of violence. Two studies (McDowell et al., 1994; Harris et al., 2016) questioned whether dental care professionals would know the procedure in case of finding signs of domestic violence (Table 4). In two studies (Carvalho et al., 2013; Harris et al., 2016), the results were displayed in graphs and the values were extracted using Adobe Photoshop (Adobe Systems, California, United States).

Three studies (Carvalho et al., 2013; Love et al., 2001; McDowell et al., 1994) provided the answers from dental care professionals about their attitudes in suspicious cases of violence against women. McDowell et al. (1994) suggested that $3 \%$ of the participants reported cases of suspected domestic violence to the authorities. Among the reasons behind professional omission in suspecious cases of violence were: the lack of knowledge about patient's medical history (37\%) and lack of knowledge on violence (33\%). Love et al. (2001) indicated that $64 \%$ of the participants would register their personal observations as notes on patients' records and would request clinical follow-up. Moreover, 54\% of the participants would talk to the patient about the alleged problem. Regarding the attitudes in practice, $10 \%$ would report to the police, $29 \%$ would provide information from victim assistance services, and $13 \%$ would arrange for patient safety. Carvalho et al. (2013) showed that the main attitude of dental care professionals $(37-40 \%)$ in public and private practices/services would communicate suspicious cases to the competent authorities. Other attitudes included talking to the patient or to the partner. Specifically in the private services, $7.1 \%$ of the participants said they would ignore a suspicious case (justifying that it was not their concern). In the public dental practice, omission reached $4.2 \%$.

Chiodo et al. (1994) provided percentages of dentists $(41.6 \%)$ and dental hygienists (40.9\%) that reported any educational background on family violence. The authors observed that only $22.4 \%$ of the dentists and $21.9 \%$ of the dental hygienists had background knowledge on the reporting procedures. Additionally, only a restricted number $(<22 \%)$ of dental care professional reported being aware of the types of violence and legal aspects behind suspicious cases.

In the study by Goff et al. (2001), education background was measured on a scale of 2-20, in which 2 represented no education at all about domestic violence. Participants' mean score was 5.9 - indicating little education or information on the topic. The study also revealed that only $2.7 \%$ of the participants performed clinical examination to search for potential signs of domestic abuse.

Danley et al. (2004) randomly assigned dentists and dental students to one of the following groups: a control group that answered two surveys without technical instructions about domestic violence; an experimental group that answered surveys before and after instructions the about violence; and an experimental group that answered to a survey only after the instructions. The technical instructions had a positive influence because participants in both experimental groups showed significantly higher scores of knowledge to identify injuries suggestive of domestic violence. 
Table 4 Summary of the main results of eligible studies

\begin{tabular}{|c|c|c|c|c|c|}
\hline Author & Question & $\begin{array}{l}\text { Knowledge of } \\
\text { reporting require- } \\
\text { ments }(\%)\end{array}$ & $\begin{array}{l}\text { Screening } \\
\text { for injuries } \\
(\%)\end{array}$ & $\begin{array}{l}\text { Perception } \\
\text { of physical } \\
\text { indicators } \\
(\%)\end{array}$ & Educational background (\%) \\
\hline \multirow[t]{2}{*}{ Chiodo et al., 1994} & $\begin{array}{l}\text { Dentists reporting educational back- } \\
\text { ground in family violence issues. } \\
\text { - Physical indicators }\end{array}$ & - & - & 41.6 & - \\
\hline & $\begin{array}{l}\text { Dentists reporting educational back- } \\
\text { ground in family violence issues. } \\
\text { - Spouse abuse }\end{array}$ & - & - & - & 15 \\
\hline \multirow[t]{2}{*}{ McDowell et al., 1994} & $\begin{array}{l}\text { No knowledge of mechanism for } \\
\text { reporting spouse abuse (Negative } \\
\text { answers) }\end{array}$ & 24 & - & - & - \\
\hline & $\begin{array}{l}\text { Knowledge of relationship of head } \\
\text { and neck injury to potential abuse - } \\
\text { Spouse abuse }\end{array}$ & - & - & 10.3 & - \\
\hline Goff et al., 2001 & $\begin{array}{l}\text { Questions are part of routine examina- } \\
\text { tion }\end{array}$ & - & 2.7 & - & - \\
\hline \multirow[t]{3}{*}{ Love et al., 2001} & $\begin{array}{l}\text { Screened for domestic violence at } \\
\text { checkups - Often or always }\end{array}$ & - & 1 & - & - \\
\hline & $\begin{array}{l}\text { Screened for domestic violence when } \\
\text { head or neck injury - Often or } \\
\text { always }\end{array}$ & - & - & 39 & - \\
\hline & $\begin{array}{l}\text { Domestic violence education - Neither } \\
\text { in dental school nor in continuing } \\
\text { education (Negative answers) }\end{array}$ & - & - & - & 43 \\
\hline Danley et al., 2004 & $\begin{array}{l}\text { Knowledge about role in recognizing } \\
\text { domestic violence? }\end{array}$ & - & - & - & - \\
\hline \multirow[t]{2}{*}{ Carvalho et al., 2013} & $\begin{array}{l}\text { Instructions about domestic violence } \\
\text { in undergraduate and/or graduate } \\
\text { studies - professional was instructed } \\
\text { and participated in the classes on } \\
\text { the topic }\end{array}$ & - & - & - & $\begin{array}{l}5.1 \text { (Public health system) } \\
7.2 \text { (Private clinics) }\end{array}$ \\
\hline & $\begin{array}{l}\text { Training for diagnosing signs of } \\
\text { domestic violence }\end{array}$ & - & - & $\begin{array}{l}47.2 \text { (Public } \\
\text { health } \\
\text { system) } \\
37.1 \\
\text { (Private } \\
\text { clinics) }\end{array}$ & - \\
\hline \multirow[t]{2}{*}{ Harris et al., 2016} & $\begin{array}{l}\text { Fulfill state reporting requirements for } \\
\text { intimate partner violence (IPV) - } \\
\text { Well prepared or quite well prepared }\end{array}$ & 22.7 & - & - & - \\
\hline & $\begin{array}{l}\text { Identify IPV indicators based on } \\
\text { patient history and physical exami- } \\
\text { nation - Well prepared or quite well } \\
\text { prepared }\end{array}$ & & & 25.6 & \\
\hline \multirow[t]{2}{*}{ Lea et al., 2017} & $\begin{array}{l}\text { How sufficient is the domestic } \\
\text { violence content in current dental } \\
\text { curricula }\end{array}$ & -- & -- & -- & 33 \\
\hline & $\begin{array}{l}\text { How likely is the dentist able to } \\
\text { recognize domestic violence-related } \\
\text { injury }\end{array}$ & -- & -- & 16 & -- \\
\hline \multirow[t]{2}{*}{ Parish et al., 2018} & $\begin{array}{l}\text { Patient history form includes question } \\
\text { about IPV }\end{array}$ & - & 7.1 & - & - \\
\hline & $\begin{array}{l}\text { Amount of training in IPV - None } \\
\text { (Negative answers) }\end{array}$ & - & - & - & 46.8 \\
\hline
\end{tabular}

-- - not reported 
Hsieh et al. (2006) performed a controlled cross-sectional study in which one group answered to a survey, watched tutorial instructions on how to approach cases of domestic violence, and then answered another survey. The control group also answered to both surveys but without watching the instructions. The participants of the study confirmed that the instructions were effective to guide their actions in situations of domestic violence. The answers to the surveys were provided on a quantitative (likert-like) scale from 1 to 7 , in which 1 was "strongly disagree" and 7 "strongly agree". Dental care professionals scored the highest values for the following sentences: "I would document the abuse in the patient's chart" (mean score $=4.2 \pm 0.1$ ), followed by "I would offer referral sources for domestic violence" (mean score $=3.8 \pm 0.1$ ).

The study by Drigeard et al. (2012) applied a comprehensive survey on domestic violence without reporting descriptive data for the identification of injuries, background education, and attitudes in situations of violence against women. However, the study showed that most of the participants (54\%) suspected of cases of violence against women (female patients).

Harris et al. (2016) showed that $22.7 \%$ of the participants (dentists and dental hygienists) knew the requirements to report intimate partner violence (these professional were self-classified as well prepared or quite well prepared). Additionally, $25.6 \%$ of the participants would be able to identify intimate partner violence indicators based on patient's history and physical examination.

Lea et al. (2016) carried out a survey with dental students and assessed their knowledge to identify injuries related to domestic violence.the study showed that $16 \%$ of the participants were "very likely" able to recognise these signs). The participants (33\%) also pointed out that domestic violence is not sufficiently provided in current academic curricula.

Parish et al. (2018) revealed that only $7.1 \%$ of the participants included a question in the anamnesis (patient history form) to screen potential intimate partner violence. Most of the dental care professionals also did not know where to refer patients experiencing intimate partner violence, and did not believe that screening signs of violence should be part of their job. In the same study, $40.86 \%$ of the participants received educational background on violence.

\section{Discussion}

Health care professionals play an important part in the detection and management of patients under veiled violence. Dental care professionals, in specific, work in close contact with the head and neck of their patients. The scientific literature highlights the role of dental care professionals to identify signs of violence against vulnerable individuals, such as children (Rodrigues et al., 2016) and the elderly (Rodrigues et al., 2017; Silva et al., 2017). Interpersonal violence in the domestic environment (re)entered the spotlight of public health sciences with the ongoing COVID-19 pandemic. In this context, women emerge as vulnerable victims of intimate partner violence. It is estimated that violence against women (physical, sexual, or psychological) is an underreported crime. Consequently, with the progressive return of regular dental activities and the decreasing incidence of new cases of COVID-19, female patients that were constantly exposed to violence at home will gradually return for dental appointments with potentially detectable signs of violence. This study investigated the scientific literature on violence against women to find out whether dental care professionals are aware of the proper identification and management of cases of domestic violence against women.

When it comes to the discussion of methods, a systematic literature review was justified based on a preliminary search (and acquired knowledge) of existing original studies in the field. To cover the broad spectrum of violence and retrieve only the original observational studies related to violence against women, a strategic search was performed. Out of the initial sample of 10,115 studies, only $0.08 \%(n=11)$ were eligible. The strategic search combined evidence on the awareness (identification) and attitudes (management) of dental care professionals related to violence against women. From a deeper methodological perspective, it must be noted that all the eligible studies were observational but none of them followed the STROBE (von Elm et al., 2008) guidelines (or any other EQUATOR-like standards). This particular issue was previously raised by the scientific literature (Franco et al., 2020) and has a direct and negative impact on data standardization. Consequently, meta-analysis are hampered giventhe lack of uniform methods and outcomes (affecting heterogeneity).

The outcomes of the present research showed that the sample of dental care professionals across studies $(\mathrm{n}=3780)$ consisted mostly of men $(\approx 77 \%)$ and general practitioners $(\approx 77 \%)$. This interesting phenomenon could highlight the behavior (including empathy or not) of male dental care professionals regarding violent situations experienced or reported by female patients. Overall, the outcomes revealed that dental care professionals lack knowledge and feel the need to be properly trained on the topic.. In general, violence against women is not addressed in the dental and dental hygiene curricula worldwide. Public health and forensic dentistry are some of the fields that usually approach the topic at undergraduate level. At higher levels (e.g. specialization or Masters), the topic may be addressed more specifically depending on the course. Specialized training programmes in public health, for instance, have strategies dedicated to managing populations in vulnerable conditions, such as women experiencing domestic violence. In 
Brazil, a non-governmental organization named "Apôlonias do Bem" combines the efforts of nearly 2000 dental care professionals to treat women affected by domestic violence. Since 2012, over 1000 women were treated with the most diverse dental care, especially oral rehabilitation with implants (https://www.uol.com.br/universa). Between 2007 and 2017, homicides (the most extreme side of violence against women) increased 1.7 and $60 \%$ for Brazilian white and black women, respectively (Cerqueira et al., 2020). The alarming rates illustrate a potential profile of the victims of violence to be found in dental practice. Recently, legal strategies, such as the Maria da Penha Law (a particular regulation of gender-based violence advocated by feminist organizations in Brazil (Ávila, 2018)) and the femicide Law n. 13.104/2015 (Messias et al., 2019), were triggered. Additionally, violence also targets more frequently women with a low level of education, income, and socioeconomic status (Figueroa et al., 2004). Based on the information exposed in the present study, educational strategies must be developed to enable the training of undergraduate and graduate students to identify signs of violence against female patients.

The scientific literature also provides evidence of the anatomic locations more frequently involved in injuries against women (Orchs et al., 1996). In 2009, Brink found neck injuries to be more associated with female victims of violence compared to males. The head and neck are anatomic regions related to the dental practice. In this context, the clinical examination must be highlighted as a two-step procedure: physical examination and anamnesis (Nieschlag et al., 2010). In both procedures, violence can be screened - in the former by a visual inspection of the head and neck and the latter by registering patient's medical history on their records.

While dental care professionals are not ideally prepared to identify signs of injury, some of them take action to manage suspicious cases in the dental office. Love et al. (2001) observed that $54 \%$ of dental care professionals would talk to the patient to share their concern regarding the alleged signs of violence. Informing the patient about protection services was reported by $29 \%$ of dental care professionals in the same study. In the study by Carvalho et al. (2013), over $40 \%$ of dental care professionals would report to the authorities. Talking about the situation could be dangerous if the offender is involved in the process. Retaliations could be expected in these circumstances, making the victims even more exposed to violence at home. In, Herman's (1998) model of recovery from trauma, establishing a safe environment is the first step to approach the victim. Prioritizing the victim a traumatic event (violence) is an act of empathy and must be followed to prevent the situation from worsening. Violence against women is a violation of human rights and the response of dental care professionals to it must consider the importance and impact of their attitudes in the lives of the victims. In Brazil, reporting domestic violence is mandatory for health care providers. More specifically, the Code of Dental Ethics allows professionals to break professional secrecy in cases of patients experiencing domestic violence (CFO, 2012). In this scenario, Brazilian professionals are not only obliged to report violence against women but are also encouraged to do it under the safety of ethics. Depending on the country and jurisdiction, telephone numbers are available to report suspicious cases, as well as websites. Rape Crisis Scotland (https://www.rapecrisisscotland.org.uk/), for instance, offers helplines dedicated to support victims of sexual violence. Given the differences between jurisdictions about the procedures to report domestic violence, evidencebased studies (e.g. in form of systematic reviews), could be useful to support the development of country-specific reporting strategies.

The combination of training for dental care professionals and strategies to support the process of assertive reporting is the ideal set up to promote optimal involvement of dental care professionals in the protection of female patients. This study screened the available literature on the topic and detected as limitations the lack of standard research models (methods) and report (outcomes), and three full-texts that were not detected. Regarding research models, studies in the field should benefit from guidelines on research methodology as an effort to aid the process of data analysis in future evidence-based reviews.. Regarding the missing full-texts, this is a common occurrence in evidence based reviews (systematic or scoping) as well, especially if the studies were not published recently. To overcome this limitation, e-mails were sent up to three times to the corresponding authors of the missing full-texts (with no success). It is also a common practice in systematic and scoping reviews the update of evidence when the literature is revisited in the future - this will be the opportunity to try subsequent contact with authors and to analyze potentially eligible full-texts. Finally, when it comes to future studies in gender-based violence and the role of dental care professional, authors should consider the evolving awereness of the gender science and the possibility of contributing to the scarce dental literature behind the LGBTQ+ patients.

\section{Conclusions}

This review identified eleven eligible studies out of 10,115 initial entries. The screened methodological designs were considerably different among studies, but overall low risk of bias was detected. Dental care professionals showed restrictions on their knowledge of domestic violence against women, as a potential result of the lack of education/training in the field. When faced with suspicious/confirmed cases of domestic violence against women, dental care professionals 
would talk to the patient or report it. In practice, reporting violence against women is mandatory in several countries and, depending on the jurisdiction, it justifies the breach of professional secrecy. Violence against women is a violation of human rights and dental care professionals must be able to identify signs of violence and to report properly. Educational training strategies in the field are encouraged.

Acknowledgements This study was partially financed by the Coordination for the Improvement of Higher Education Personnel - Brazil (CAPES) - Finance Code 001. We also appreciate the support of the Council for Scientific and Technological Development - Brazil (CNPq) - Finance Code 307808/2018-1.

\section{Declarations}

Conflict of Interest The authors have no conflicts of interest to disclose.

\section{References}

Aromataris, E., \& Munn, Z. (Eds.). (2020). JBI manual for evidence synthesis. JBI.

Ávila, T. P. (2018). Facing domestic violence against women in Brazil: Advances and challenge. International Journal of Crime, Justice and Social Democracy, 7(1), 15-29. https://doi.org/10.5204/ijcjsd. v7i1.397

Barbara, G., Facchin, F., Micci, L., Rendiniello, M., Giulini, P., Cattaneo, C., et al. (2020). COVID-19, lockdown, and intimate partner violence: Some data from an Italian service and suggestions for future approaches. Journal of Women's Health (Larchmt), 29(10), 1239-1242. https://doi.org/10.1089/jwh.2020.8590

Brink, O. (2009). When violence strikes the head, neck, and face. The Journal of Trauma, 67(1), 147-151. https://doi.org/10.1097/ta. 0b013e318182f77f

Carvalho, L. M. F., Galo, R., \& Silva, R. H. A. (2013). O cirurgiãodentista frente à violência doméstica: conhecimento dos profissionais em âmbito público e privado. Medicina (Ribeirão Preto), 46(3), 297-304. doi: 10.11606/issn.2176-7262.v46i3p297-304*.

Cerqueira, D., Lima, R. S., Bueno, S., Lima, R. S., Silva, E. R. A., Ferreira, H., et al. (2020). Atlas de violência. IPEA.

CFO. (2012). Code of dental ethics - Approved by resolution 118/2012. Conselho Federal de Odontologia.

Chiodo, G. T., Tilden, V. P., Limandri, B. J., \& Schmidt, T. A. (1994). Addressing family violence among dental patients: Assessment and intervention. The Journal of the American Dental Association, 125, 69-75. 10.14219/jada.archive.1994.0004*.

Danley, D., Gansky, S. A., Chow, D., \& Gerbert, B. (2004). Preparing dental students to recognize and respond to domestic violence: The impact of a brief tutorial. Journal of American Dental Association, 135(1), 67-73. 10.14219/jada.archive.2004.0022*.

Drigeard, C., Nicolas, E., Hansjacob, A., \& Roger-Leroi, V. (2012). Educational needs in the field of detection of domestic violence and neglect: The opinion of a population of French dentists. European Journal of Dental Education, 16, 156-165. 10.1111/j.1600-0579.2012.00739.x*.

Figueroa, M. D., Millán-Guerrero, R. O., Estrada-López, M., IsaisMillán, R., Bayardo-Quezada, C., Trujillo-Hernández, B., \& Tene, C. E. (2004). Physical abuse of women. Gaceta Médica de Mexico,140(5), 481-484.
Flury, M., Nyberg, E., \& Riecher-Rössler, A. (2010). Domestic violence against women: Definitions, epidemiology, risk factors and consequences. Swiss Medical Weekly, 140, w13099. https:// doi.org/10.4414/smw.2010.13099

Franco, R. P. A. V., Franco, A., Fernandes, M. P., Pinheiro, A. A., \& Silva, R. H. A. (2020). Radiographic assessment of the influence of metopism in frontal sinus morphology - A systematic review. Research, Society and Development, 9(10), e5719108993. 10.33448/rsd-v9i10.8993.

Goff, H. W., Byrd, T. L., Shelton, A. J., \& Parcel, G. S. (2001). Health care professionals' skills, beliefs, and expectations about screening for domestic violence in a border community. Family \& Community Health, 24(1), 39-54. 10.1097/00003727-200104000-00007*.

Harris, C. M., Boyd, L., Rainchuso, L., \& Rothman, A. T. (2016). Oral health care providers' knowledge and attitudes about intimate partner violence. Journal of Dental Hygiene, 90(5), 283-296*.

Herman, J. L. (1998). Recovery from psychological trauma. Psychiatry and Clinical Neurosciences, 52(1), S145-S150.

Hsieh, N. K., Herzig, K., Gansky, S. A., Danley, D., \& Gerbert, B. (2006). Changing dentists' knowledge, attitudes and behavior regarding domestic violence through an interactive multimedia tutorial. Journal of the American Dental Association, 137, 596603. 10.14219/jada.archive.2006.0254*.

Krug, E. G., Dahlberg, L. L., Mercy, J. A., Zwi, A. B., \& Lozano, R. (Eds.). (2002). World report on violence and health. World Health Organization.

Lea, S. J., Quinn, B., \& Reynolds, P. (2016). The role and education of dental care professionals in identifying domestic violence: Report of an audience participation exercise and round table discussion. Technology, Knowledge and Learning, 22(2):219-226. 10.1007/ s10758-016-9293-9*.

Love, C., Gerbert, B., Caspers, N., Bronstone, A., Perry, D., \& Bird, W. (2001). Dentists' attitudes and behaviors regarding domestic violence: The need for an effective response. Journal of the American Dental Association, 132, 85-93.*10.14219/jada. archive.2001.0032.

McDowell, J. D., Kassebaum, D. K., \& Fryer, G. E. (1994). Recognizing and reporting domestic violence: A survey of dental practitioners. Special Care in Dentistry, 14(2), 49-53. 10.1111/j.17544505.1994.tb01099.x*.

Messias, E. R., Carmo, V. M., \& Almeida, V. M. (2019). Femicide: An analysis from the perspective of the human person's dignity. Revista de Estudos Feministas, 28(1), e60946. https://doi.org/10. 1590/1806-9584-2020v28n160946

Moola, S., Munn, Z., Tufanaru, C., Aromataris, E., Sears, K., Sfetc, R., Currie, M., Lisy, K., Qureshi, R., Mattis, P., \& Mu, P. F. (2020). Chapter 7: Systematic reviews of etiology and risk. In E. Aromataris \& Z. Munn (Eds.), JBI manual for evidence synthesis. JBI.

Moreira, D. N., \& Costa, M. P. (2020). The impact of the Covid-19 pandemic in the precipitation of intimate partner violence. International Journal of Law and Psychiatry, 271, 101606. https://doi. org/10.1016/j.ijlp.2020.101606

Nieschlag, E., Behre, H. M., \& Nieschlag, S. (2010). Andrology (3rd ed.). Springer-Verlag.

OHCHR-Office of the High Commissioner for Human Rights. (1993). Declaration on the elimination of violence against women. UN.

Page, M. J., McKenzie, J. E., Bossuyt, P. M., Boutron, I., Hoffmann, T. C., Mulrow, C. D., et al. (2021). The PRISMA 2020 statement: An updated guideline for reporting systematic reviews. BMJ, 372, n71. https://doi.org/10.1136/bmj.n71

Parish, C. L., Pereyra, M. R., Abel, S. N., Siegel, K., Pollack, H. A., \& Metsch, L. R. (2018). Intimate partner violence screening in the dental setting: Results of a nationally representative survey. Journal of the American Dental Association (1939), 149(2), 112-121. https://doi.org/10.1016/j.adaj.2017.09.003 
Rodrigues, J., Lima, A., Nagata, J. Y., Rigo, L., Cericato, G. O., Franco, A., \& Paranhos, L. R. (2016). Domestic violence against children detected and managed in the routine of dentistry - a systematic review. Journal of Forensic and Legal Medicine, 43, 34-41. https://doi.org/10.1016/j.jflm.2016.07.006

Rodrigues, J. L. S. A., Paranhos, L. R., \& Rode, S. M. (2017). The importance of dentistry in cases of domestic violence and neglect against the elderly. Journal of Oral Research, 6(6), 140-141. 10.17126/joralres.2017.035.

Sánchez, O. R., Vale, D. B., Rodrigues, L., \& Surita, F. G. (2020). Violence against women during the COVID-19 pandemic: An integrative review. International Journal of Gynaecology and Obstetrics, 151(2), 180-187. https://doi.org/10.1002/ijgo.13365

Shamseer, L., Moher, D., Clarke, M., Ghersi, D., Liberati, A., Petticrew, M., et al. (2015). Preferred reporting items for systematic review and meta-analysis protocols (PRISMA-P) 2015: Elaboration and explanation. BMJ, 350, g7647. https://doi.org/10.1136/ bmj.g7647
Silva, L. O., Souza-Silva, B. N., de Alcântara Rodrigues, J. L., Rigo, L., Cericato, G. O., Franco, A., \& Paranhos, L. R. (2017). Identification and management of elder physical abuse in the routine of dentistry - a systematic review. Gerodontology, 34(1), 3-12. https://doi.org/10.1111/ger.12252

von Elm, E., Altman, D. G., Egger, M., Pocock, S. J., Gøtzsche, P. C., Vandenbroucke, J. P., \& Initiative, S. T. R. O. B. E. (2008). The strengthening the reporting of observational studies in epidemiology (STROBE) statement: Guidelines for reporting observational studies. Journal of Clinical Epidemiology, 61(4), 344-349. https:// doi.org/10.1016/j.jclinepi.2007.11.008

World Health Organization. (1996). Global consultation on violence and health. Violence: A public health priority. WHO.

World Health Organization. (2018). Violence against women prevalence estimates, 2018. WHO.

Publisher's Note Springer Nature remains neutral with regard to jurisdictional claims in published maps and institutional affiliations. 